\title{
Espaços de fazer como geradores de uma cultura pautada pela antidisciplinaridade, tolerância ao erro e diversidade cognitiva
}

\section{Gabriela da Costa Aguiar Agustini ${ }^{1}$ Jorge Roberto Lopes dos Santos ${ }^{2}$}

\begin{abstract}
Resumo: Este artigo propõe que três valores assumem um papel importante no estímulo à geração de novas ideias e ampliação do acesso ao conhecimento, quando incorporados às práticas dos espaços de aprendizagem tecnológica (os espaços de fazer, chamados aqui de labs). São eles: antidisciplinaridade, tolerância ao erro e diversidade cognitiva. $O$ trabalho se insere no contexto marcado pela democratização de tecnologias que permitem a cidadãos fora de grandes centros de pesquisa e da indústria materializar suas ideias, expressar sua visão de mundo, sua criatividade e construir conhecimento a partir da interação com artefatos. E busca contribuir para reflexões sobre a sociedade digital e a necessidade de entendermos os fazeres tecnológicos a partir de seus aspectos culturais.
\end{abstract}

Palavras-chave: experimental; design; criatividade; cultura digital; makerspaces.

Espacios de hacer como generadores de una cultura guiada por la antidisciplinariedad, la tolerancia al error y la diversidad cognitiva.

Resumen: Este artículo propone que tres valores tienen un papel importante en estimular la generación de nuevas ideas y expandir el acceso al conocimiento, cuando se incorporan a las prácticas de los espacios de aprendizaje tecnológico (los espacios para hacer, aquí llamados laboratorios). Ellos son: antidisciplinariedad, tolerancia al error y diversidad cognitiva. El trabajo se inserta en el contexto marcado por la democratización de las tecnologías que permiten a los ciudadanos fuera de los principales centros de investigación y la industria materializar sus ideas, expresar su visión del mundo, su creatividad y generar conocimiento a partir de la interacción con los

\footnotetext{
${ }^{1}$ Gabriela da Costa Aguiar Agustini. Mestre em Design, Tecnologia e Sociedade pelo Departamento de Artes \& Design da PUC Rio. Professora do MBA de Gestão cultural da Universidade Cândido Mendes, Rio de Janeiro, Brasil. E-mail: gabiagustini@gmail.com- http://orcid.org/0000-0002-41701992

${ }^{2}$ Jorge Roberto Lopes dos Santos. Doutor em Design Products pelo Royal CollegeofArt, Reino Unido. Professor Departamento de Artes \& Design da Pontifícia Universidade Católica do Rio de Janeiro, Brasil. E-mail: jorge.lopes@puc-rio.br - https://orcid.org/0000-0002-8162-8291
} 
artefactos. Y busca contribuir a reflexiones sobre la sociedad digital y la necesidad de comprender las prácticas tecnológicas basadas en sus aspectos culturales.

Palabras clave: experimental; design; creatividad; cultura digital; espacios de hacer.

Makerspaces as a generators of a culture guided by antidisciplinarity, toleranceforfailure, and diversity.

\begin{abstract}
This article proposes that three values assume an important role in stimulating the generation of new ideas and expanding access to knowledge, when guiding practices of technological learning spaces (makerspaces). They are: antidisciplinarity, tolerance for failure and diversity. The work is inserted in the context marked by the democratization of technologies that allow citizens outside major research centers and industry to materialize their ideas, express their worldview, their creativity and build knowledge from the interaction with artifacts. And it seeks to contribute to reflections on the digital society and the need to understand technological practices based on their cultural aspects.
\end{abstract}

Keywords: experimental; design; creativity; digital culture; makerspaces.

\title{
Espaços de fazer como geradores de uma cultura pautada pela antidisciplinaridade, tolerância ao erro e diversidade cognitiva
}

\section{Introdução}

Este artigo traz uma reflexão a respeito do fazer como prática de aprendizagem, ressaltando 0 seu potencial de irradiar valores que contribuem para a geração de novas ideias e ampliação do acesso ao conhecimento. O ponto de partida é a observação do uso que os cidadãos, neste início do século XXI, fazem das ferramentas de criação experimental e de desenvolvimento disponíveis em espaços de criatividade conhecidos por nomes diversos, tais como makerspaces, fablabs, hackerspaces, laboratórios cidadãos ou simplesmente laboratórios (os chamamos de labs neste artigo).

Busca-se entender como o ato de produzir artefatos pode se constituir em uma ferramenta importante de geração e de expressão de novos pensamentos, colaborar para um processo de aprendizagem e no desenho de futuros desejáveis. E, para que isso ocorra, entende-se ser necessária a presença de três valores: antidisciplinaridade, tolerância ao erro e diversidade cognitiva - explicados neste artigo.

Esta proposição parte dos repertórios dos autores somados à leitura crítica de trabalhos recentes conceituados globalmente e busca estimular a reflexão 


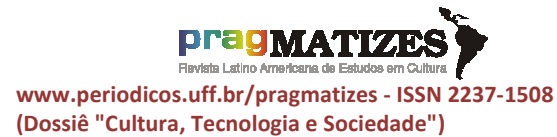

sobre 0 importante papel que a experimentação pode desempenhar na construção de futuros desejáveis.

\subsection{Construindo conhecimento a partir da produção de artefatos}

Os objetos não são mera execução de um pensamento pré-concebido, mas sim o resultado de um diálogo entre criador e materiais - o que enfatiza o protagonismo dos cidadãos na construção de artefatos.

Tim Ingold defende o desenhar como "um processo de pensamento, e não a projeção de um pensamento" e explica que "a tarefa do produtor consiste em trazer as peças para um engajamento, de maneira que cheguem a uma correspondência mútua" (INGOLD, 2013, p. 128 e 69, respectivamente).

Para Ingold, o processo de produção não é fruto da dominação do produtor sobre os materiais com que trabalha, mas sim da convergência entre ambos. Dessa convergência resulta um processo que 0 autor chama de "crescimento", e não de produção, termo usualmente atribuído a produtos. Ingold, assim, compara os artefatos a organismos vivos e afirma que, tal como estes, os produtos crescem e são moldados. A visão do britânico resgata um pensamento pré-moderno defendido por gregos clássicos, que considera o trabalho do artesão na manipulação de materiais não como fruto de um pensamento racional e sim como uma "inscrição na ordem da natureza", como percebido por Pedro Pereira Leite (2002).

Entender esse diálogo entre materiais e pessoas na construção de objetos ajuda a explicar a importância de se explorarem as atividades manuais enquanto ferramentas de aprendizagem. $E$, nesse sentido, diversos pesquisadores apontam que usar as mãos para criar, explorar e comunicar é natural para os humanos. Como escreve Dale Dougherty (2016, p. XVI-XVII):

Fazer é um tipo de 'e se', explorando questões sobre como algo funciona e se ele poderia funcionar de maneira diferente. [...]

Fazer é uma liberdade criativa que aprendemos a apreciar através da prática. Podemos melhorar e, como resultado, há mais ainda que podemos fazer. Nós não sabemos se temos algum talento especial para isso até sujarmos as mãos e tentarmos. Através da prática de fazer, desenvolvemos 0 que chamamos de mentalidade de 'poder fazer' que nos encoraja a agir, assumir o controle de nossas vidas e desenvolver nossas próprias capacidades. Fazer nos envolve plena e profundamente como seres humanos e satisfaz nossas almas criativas.

Também valiosa a contribuição de Trevor H. J. Marchand, para quem "dominar uma ferramenta modifica e expande nossas capacidades cognitivas e físicas integradas. Ferramentas são 
artefatos culturais que possuem sua própria história de uso e significado compartilhado e, através da prática, somos, por assim dizer, 'socializados na ferramenta"' (MARCHAND, 2012, p. 209).

$E$ esse fazer não se restringe ao desenvolvimento de produtos físicos a partir do zero: ele também se manifesta no conserto de produtos avariados e até mesmo na construção de artefatos digitais. A esse respeito, é essencial a leitura de Eterna vigilância: como montei e desvendei o maior sistema de espionagem do mundo, de Edward Snowden.

$\mathrm{Na}$ obra, Snowden descreve sua trajetória pela Agência Central de Inteligência (CIA - em inglês) e pela Agência de Segurança Nacional (SNA - em inglês). Ele começa por resgatar suas primeiras memórias de interação com computadores e reforça o quanto de sua curiosidade sobre 0 funcionamento de máquinas foi formada enquanto manuseava equipamentos eletrônicos, às vezes até para consertálos:

Um dia, meu surrado cartucho do Super Mario Bros. não carregava, por mais que eu soprasse dentro dele. Era o que tínhamos de fazer naquela época - ou o que achávamos que tínhamos de fazer: soprar na parte aberta do cartucho para tirar a poeira, detritos e pelos dos animais que tendiam a se acumular ali. [...]
E o pior de tudo é que meu pai havia acabado de viajar [...]. Por isso resolvi consertar o troço sozinho. Se eu conseguisse, sabia que meu pai ficaria impressionado. [...]

Concluí que, para descobrir o que havia de errado com aquela coisa, eu primeiro teria que desmontá-la. Basicamente, eu estava só copiando - ou tentando copiar - os mesmos movimentos que meu pai repetia toda vez que se sentava à mesa da cozinha para consertar o videocassete ou o aparelho de som [...]. Demorei cerca de uma hora para desmontar o console. [...] mas, por fim, não consegui. [...]

Meu pai não ficaria orgulhoso de mim [...]. Para os seus colegas, meu pai era um engenheiro de sistemas eletrônicos especializado em aviônica. Para mim, ele era um cientista louco que tentava consertar tudo sozinho [...]. Eu era seu ajudante sempre que ele deixava, e ia conhecendo tanto os prazeres físicos do trabalho manual quanto os prazeres intelectuais da mecânica básica, além dos princípios fundamentais da eletrônica [...]. Todos os trabalhos que realizamos juntos acabavam em um conserto bem-sucedido ou em um palavrão [...]. Eu nunca o julgava por esses fracassos; sempre ficava impressionado demais com o fato de ele ser ousado e se arriscar a tentar. Quando ele voltou para casa e descobriu o que eu havia feito com o NES [...]. Ele me explicou que entender como e por que não havia dado certo era tão importante quanto entender qual componente estava com defeito; descobrir o como e o porquê permitiria evitar que acontecesse o mesmo defeito no futuro. (SNOWDEN, 2019, p. 27-29). 


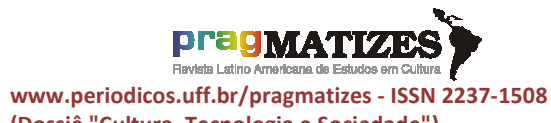

(Dossiê "Cultura, Tecnologia e Sociedade")
O relato de Snowden revela: 1) o potencial que a curiosidade tem para mover o aprendizado humano; 2) como é possível trabalhar com conceitos teóricos a partir da prática, estimulando conexões entre ambos; 3) o quanto as áreas do conhecimento começam a se dissolver quando olhamos para o cotidiano; 4) como a lógica de "tentativa e erro" pode ajudar na aprendizagem de uma série de conhecimentos técnicos; e 5) que entender o próprio erro é uma excelente forma de guiar 0 processo de aprendizagem.

A memória de infância de Snowden também possui serventia para que se reflita a respeito de um aspecto importante do chamado universo maker ${ }^{3}$, essencial para se compreender o escopo

${ }^{3} \mathrm{O}$ anglicismo "maker" é o nome dado pelas comunidades de design, tecnologia e inovação às pessoas que produzem artefatos, tendo elas formação técnica para tanto ou não. Está associado ao crescimento da cultura mão-namassa, à possibilidade de criação, ao design e à inovação (DOUGHERTY, 2012):

Uma marca registrada do movimento maker é a mentalidade faça você mesmo (do inglês Do It Yourself), que reúne indivíduos em torno de atividades diversas, incluindo artesanato têxtil, robótica, culinária, artesanato em madeira, eletrônica, fabricação digital, reparo mecânico, ou criação e produção de quase tudo. Apesar de sua diversidade, o movimento é unificado por um compromisso em torno de atividades diversas, incluindo artesanato têxtil, robótica, culinária, artesanato em madeira, eletrônica, compartilhado de exploração aberta, interesse intrínseco e ideias criativas (Bravi; Santos; Murmura, 2018, p. 1339). do presente artigo: a educação por meio da "mão na massa".

Um dos grandes defensores do "aprender fazendo", Seymour Papert, citado por Dougherty (2016, p. 185), afirma, inclusive, que as crianças constroem mais facilmente novos conhecimentos quando estão, de fato, construindo algo real. $\mathrm{Na}$ análise de Edith Ackermann (2015, p. 8), ele chama atenção para o que considera meios poderosos de alcançar compreensão a respeito de algo: "mergulhar" nas situações em vez de olhar para elas a distância, estar conectado, e não separado, do objeto de análise.

Papert, um dos maiores visionários no uso de tecnologias digitais na educação, compartilha do mesmo entusiasmo de Paulo Freire ao entender o aluno como protagonista em seu processo de aprendizagem. Tanto o sul-africano quanto 0 brasileiro acreditam na importância de se abrir espaço para que os interesses e paixões do aluno prosperem.

Entre 1967 e 1968, Papert desenvolveu uma linguagem de programação de computadores totalmente voltada para a educação, a Logo, e suas teorias embasam boa parte dos estudos que pensam os computadores como instrumento de aprendizagem. Como lembra Paulo Blikstein (2018, p. 420-421): 


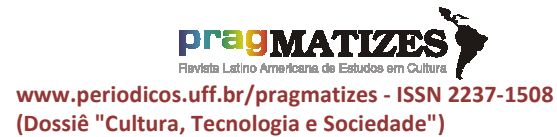

Depois de trabalhar com Jean Piaget em Genebra por vários anos, Papert acrescentou à teoria construtivista a ideia de que as interações e experiências dos alunos aconteceriam com mais vigor se os alunos se engajassem na construção de artefatos públicos e compartilháveis, como robôs, invenções, castelos de areia ou programas de computador. Papert elevou 0 status cognitivo de construção e fabricação e reavaliou a relação hierárquica entre abstrato e concreto.

Outro entusiasta do "aprender fazendo", o filósofo John Dewey enunciou, no início do século $X X$, as vantagens comparativas do fazer para a construção do conhecimento. Para ele, conforme relata Nils Gore (2004, p. 8), essa é uma forma de estimular o aluno a pensar sobre os assuntos de maneiras mais complexas do que com a "artificialidade peculiar (que) atribui a muito do que é ensinado nas escolas". Ainda segundo Gore, o pensamento de Dewey defende que a exploração com projetos de base material, criados à mão, promove o desenvolvimento de um discurso crítico entre criador e objeto e entre criador e seus críticos ou colegas.

\subsection{Aprender fazendo}

As visões de Dewey, Piaget, Freire, Papert, dentre outros, fornecem a base conceitual, neste século XXI, a muitos dos pensamentos por trás de ações ligadas ao ensino de tecnologia nas escolas, em especial às que se valem de metodologias ligadas aos fazeres manuais.

Eles nos lembram que aprender, especialmente hoje, é muito menos adquirir informações ou submeter-se a ideias ou valores de outras pessoas do que colocar as próprias palavras ao mundo ou encontrar a própria voz e trocar ideias com outras pessoas (ACKERMANN, 2015, p. 2).

A primeira e mais óbvia impressão a respeito desses espaços e políticas educacionais é a de que eles servem como suporte para 0 ensino de habilidades técnicas conectadas ao universo digital e computacional, preparando crianças, adolescentes e jovens adultos para as profissões e empregos do futuro. No entanto, como defende Papert, a tecnologia nas escolas pode ter um papel mais importante e funcionar como ferramenta emancipatória que coloca os materiais de construção mais poderosos nas mãos das crianças. "As máquinas e ferramentas disponibilizadas pela revolução maker já comprovaram permitir aos alunos projetar e construir objetos e invenções inimagináveis e atender muitas formas de trabalhar, expressar e construir", conforme aponta Blikstein (2018, p. 434-435). 
AGUSTINI, Gabriela da Costa Aguiar; SANTOS, Jorge Roberto Lopes dos. Espaços de fazer como geradores de uma cultura pautada pela antidisciplinaridade, tolerância ao erro e diversidade cognitiva.

PragMATIZES - Revista Latino-Americana de Estudos em Cultura,

Niterói/RJ, Ano 10, n. 19, p. 30-50, set. 2020.

Blikstein continua por destacar as potencialidades do movimento maker no ambiente escolar:

Existem duas maneiras pelas quais o movimento maker pode ser radicalmente inovador. Primeiro, indo além das visões estereotipadas da educação técnica e rompendo a dicotomia entre trabalho prático e intelectual. Segundo, quando, operando nas escolas, o movimento maker puder prestar atenção especial às ideias da psicologia do desenvolvimento, do design de interação, do construcionismo e da educação progressiva (BLIKSTEIN, 2018, p. 434).

À luz da realidade brasileira, e na busca por soluções nacionais que contribuam para equidade e diversidade na educação maker, Rodrigo Barbosa e Silva e Luiz Ernesto Merkle elencam três aspectos importantes que devem guiar o trabalho em escolas: "primeiro, reconhecer as aspirações e práticas dos alunos, segundo, pensar e promover práticas de aprendizado pelo fazer, e terceiro, 0 relacionamento entre estudantes e suas próprias necessidades enquanto participantes cidadãos da sociedade" (SOLVA; MERKLE, 2016, p. 7).

O diálogo dos espaços de fazer com os problemas sociais que rodeiam as escolas e permeiam a vida dos estudantes é defendido por Blikstein, cujo trabalho

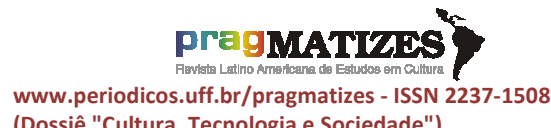

(Dossiê "Cultura, Tecnologia e Sociedade")

teórico promove a aproximação do pensamento de Papert com 0 de Paulo Freire:

Freire defende uma ideia aparentemente simples: o aluno não é um receptáculo de informações, uma cabeça vazia onde 'depositamos' conteúdos - o que Freire chamou de "educação bancária”. O aluno é um intelectual ativo que tem suas próprias ideias, teorias e sonhos; além disso, ele está imerso em práticas sociais e culturais muito particulares. Freire criou uma teoria educacional baseada na ideia de que, em primeiro lugar, o currículo escolar como o conhecemos já nasceu errado; não se pode ensinar uma criança na Vila Madalena em São Paulo e no Sertão nordestino com o mesmo livro. Em segundo lugar, educação não deve adestrar a criança, mas prepará-la para o que Freire chama de "emancipação", ou seja, usar o conhecimento para encontrar seu lugar no mundo e transformá-lo (BLIKSTEIN, sem data, p. 8).

Citando o trabalho de Edward Deci e Richard Ryan, Blikstein (s. d., p. 9) aponta a importância de se repensar os conteúdos e as ferramentas utilizados em sala de aula, permitindo que "os alunos criem modelos e explorem a ciência [tal] como se faz ciência hoje em dia". A dupla de autores apresenta a noção de como a motivação dos alunos é fator chave de sucesso em qualquer projeto educacional e elenca alguns componentes fundamentais para que isso ocorra. São 


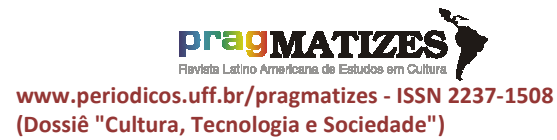

eles: a autonomia (a noção de estar em controle das próprias ações), a competência (ser capaz de ter um efeito socialmente valorizado no ambiente em que se vive) e o relacionamento interpessoal (sentir-se conectado a outras pessoas).

Blikstein avança na questão da autonomia, recorrendo aos estudos de Alfred Bandura e Carol Dweck, nos seguintes termos:

Quando pais e professores veem um aluno desinteressado e desmotivado, não é mera coincidência ou vagabundagem. Por que ele está desmotivado? Em primeiro lugar, o princípio da autonomia é diariamente violentado na escola. Os alunos se sentem parte de um grande rebanho humano, todos fazendo a mesma coisa, todos aprendendo o que já é sabido há séculos, e todos seguindo a mesma trajetória, independentemente de seus interesses e aspirações pessoais. Em segundo lugar, o princípio da competência é também violentado: quanto do que se faz na escola tem alguma importância para o mundo? (BLIKSTEIN, s. d., p. 9-10).

Para ilustrar, Blikstein conta no mesmo artigo a história de um estudante da rede pública da Zona Leste de São Paulo que, aos doze anos, participou de um desafio em sua escola. O objetivo era estimular os alunos a olhar para o seu entorno e propor soluções criativas que fizessem sentido no contexto local. "Eles pesquisavam problemas na cidade que os preocupavam, como poluição, violência, qualidade da água, transporte público, conservação de energia ou saneamento básico, coletavam dados, refletiam sobre possíveis alternativas e criavam protótipos para solucioná-los", explica (BLIKSTEIN, s. d., p. 1).

O aluno descrito por Blikstein resolveu trabalhar na geração de energia e propôs o uso de lombadas que capturassem a energia da rotação dos pneus e do peso do carro. Em três semanas, conseguiu fazer um protótipo com uma placa de robótica programável conectada a diversos componentes eletrônicos (materiais com os quais ele entrava em contato pela primeira vez). Criar o protótipo exigiu que 0 aluno aprendesse robótica, programação de computadores e elementos de engenharia mecânica e elétrica.

Segundo Blikstein, sete anos mais tarde, uma grande empresa nos Estados Unidos havia começado a instalar lombadas que geravam energia, seguindo exatamente o projeto do aluno - que, a propósito, havia ingressado na faculdade de engenharia.

O objetivo deste trabalho não é se aprofundar nos diferentes formatos da inclusão do movimento maker em escolas e universidades. No entanto, convém reconhecer sua existência e algumas de suas bases teóricas. Com base nisso, é possível levantar um questionamento feito 


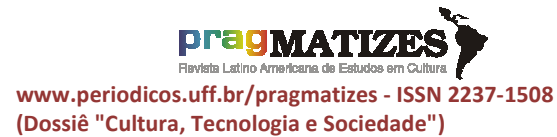

por Blikstein a respeito da capacidade das escolas de transformarem suas culturas e, assim, permitir que o movimento maker sobreviva em ambientes escolares:

Uma preocupação fundamental é
garantir que esse movimento não se
junte a laptops, tablets e aprendizado
baseado em vídeo na longa lista de
modismos educacionais exagerados
das últimas décadas. Uma segunda
questão é que, na própria história da
educação tecnológica, é comum as
atividades práticas serem
consideradas tarefas de segunda
classe nas escolas, inferiores ao
trabalho escolar e associadas
apenas à educação técnica e
profissional (Bennett, 1937 ).
(BLIKSTEIN, 2018, p. 421).

Apesar de experiências de níveis e impactos muito diferentes, este estudo parte da ideia de que um indivíduo estimulado desde a infância a "pôr a mão na massa", montando e desmontando aparatos, terá a possibilidade de desenvolver ou aprimorar habilidades que influenciarão sua forma de se relacionar com os objetos, com as pessoas e também com o universo ao seu redor.

\subsection{Cultura: antidisciplinaridade,} tolerância ao erro e diversidade
cognitiva como valores

O movimento maker e a cultura dos laboratórios tecnológicos experimentais tensionam a forma tradicional de transmissão de conhecimento, baseada em uma autoridade central (o professor), que ensina os conteúdos aos alunos a partir de uma posição hierarquicamente superior. Em contraposição a isso, esses espaços, chamados aqui de labs, apresentam uma forma de educação guiada pelo interesse dos participantes, que são ativos nessa construção do conhecimento e dispõem de um conjunto amplo de ferramentas e materiais para trilhar o seu processo de aprendizado.

Como afirmam Ito e Howe, "educação é o que outras pessoas fazem por você. Aprender é o que você faz por você mesmo" (2016, p. 167). Esses laboratórios são sobre o aprender. E não apenas porque atendem a recortes de população que extrapolam o público habitual das instituições de ensino, mas porque promovem uma nova cultura, que estimula o cidadão, independentemente de sua formação ou contexto cultural, a se entender como um agente em constante processo de aprendizagem.

É por isso que Erica Halverson e Kimberly Sheridan defendem que o movimento maker pode "transformar como entendemos 0 que conta como aprendizado, como aprendiz e como ambiente de aprendizagem" (2014, p. 496). Citados por Haverson e Sheridan, Kafai, Fields e Searle, por sua vez, propõem que "os estudantes passem a ser vistos como solucionadores de problemas e questionadores e os 
professores como mentores, guias, produtores" (HALVERSON; SHERIDAN, 2014, p. 496).

Elizabeth Garber, Lisa Hochtritt e Manisha Sharma resumem bem laboratórios focados no fazer: "a ideia de mexer com materiais, compartilhar e aprender fazendo em um ambiente que apoia e incentiva a curiosidade está no centro do movimento maker" (2019, p. 9). Os autores reforçam que esses espaços foram desenhados para serem colaborativos, flexíveis e terem áreas em diálogo. Ou seja, é justamente na capacidade experimental que reside sua maior potência.

À luz do que foi dito, o presente artigo entende que esses espaços têm o potencial de representar impacto na transformação cultural do seu entorno (seja ele uma escola, uma empresa, um museu, um centro de pesquisa, uma universidade ou mesmo um bairro) e estimular reflexão e produção crítica. Para isso, no entanto, é necessário que eles sejam pautados por alguns valores, dos quais ressaltamos aqui: antidisciplinaridade, tolerância ao erro e diversidade cognitiva. Tais valores são analisados nos subtópicos abaixo.

\subsubsection{Antidisciplinaridade}

Ito acredita que a forma como a educação tradicional ainda funciona nestas primeiras décadas do século XXI contribui "para uma hiperespecialização, na qual pessoas em diferentes áreas têm dificuldade em colaborar - ou mesmo se comunicar - com pessoas em diferentes campos" $(2016)^{4}$.

Pensando a integração das áreas do conhecimento e a aproximação das artes com as ciências, a pesquisadora Neri Oxman, do Medialab MIT, propôs em 2016 o Ciclo de Kreb da Criatividade (KCC), um modelo conceitual que é uma tentativa de representar a hipótese antidisciplinar: que o conhecimento não pode mais ser atribuído a disciplinas específicas, ou produzido dentro de limites disciplinares, mas que está totalmente enredado.

O objetivo é estabelecer uma cartografia experimental, ainda holística, da inter-relação entre esses domínios, em que um domínio pode incitar a (r)evolução dentro de outro; e onde um único indivíduo ou projeto pode residir em vários domínios (OXMAN, 2016).

A proposta de Oxman explica como as modalidades da criatividade humana (definidas por ela como ciência, engenharia, design e arte) se relacionam, uma alimentando a outra:

O papel da ciência é explicar e prever o mundo ao nosso redor; 'converte' informações em conhecimento. $O$ papel da engenharia é aplicar o conhecimento

\footnotetext{
${ }^{4}$ https://jods.mitpress.mit.edu/pub/designandsci ence.
} 


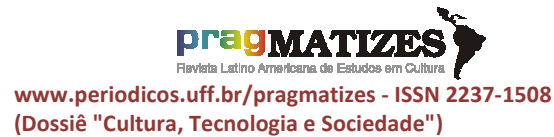

científico ao desenvolvimento de soluções para problemas empíricos; 'converte' o conhecimento em utilidade. O papel do design é produzir modalidades de soluções que maximizem a função e aumentem a experiência humana; 'converte' a utilidade em comportamento. O papel da arte é questionar o comportamento humano e criar consciência do mundo à nossa volta; 'converte' o comportamento em novas percepções de informações, apresentando novamente os dados que iniciaram o KCC na Ciência (Oxman, 2016).

A ciência produz conhecimento que é usado pelos engenheiros. A engenharia produz utilidade usada por designers. Os designers produzem mudanças no comportamento que são percebidas pelos artistas. A arte produz novas percepções do mundo, concedendo acesso a novas informações de dentro, sobre ele e inspirando novas investigações científicas (OXMAN, 2016).

Ito diferencia 0 trabalho interdisciplinar, resultado do trabalho conjunto de pessoas de diferentes disciplinas, do antidisciplinar, que consiste em "trabalhar em espaços que simplesmente não se encaixam em nenhuma disciplina acadêmica existente um campo de estudo específico com suas próprias palavras, estruturas e métodos" (ITO, 2016 $)$.

\footnotetext{
${ }^{5}$ https://jods.mitpress.mit.edu/pub/designandsci ence.
}

A abordagem antidisciplinar é uma resposta à dificuldade de se encaixarem determinados problemas nas disciplinas tradicionais. Um exemplo citado por Ito no mesmo artigo é o do corpo humano, perfeito em desafiar a interdisciplinaridade porque as diferentes disciplinas parecem trançar um mosaico complexo que frequentemente dificulta a compreensão do objeto "porque nossa linguagem é muito diferente e nossos microscópios são definidos de maneira tão diferente". Para Ito, a melhor chance de desvendar as complexidades do corpo humano viria por meio de uma "One Science" colaborativa.

Outro exemplo da antidisciplinaridade apontado pelo autor no artigo é o movimento que formou a cibernética nas décadas de 1940 e 1950, reunindo engenheiros, designers, cientistas, matemáticos, sociólogos, filósofos, linguistas, psicólogos e pensadores de outros campos. Atraídos pelo entendimento de como os sistemas biológicos regulavam o movimento e até as aplicações do controle de mísseis balísticos, eles se reuniram para investigar os sistemas e os ciclos de feedback como uma maneira de compreender e projetar sistemas complexos.

Ao criar espaços para projetos e ideias que estejam entre ou além das disciplinas, os laboratórios experimentais contribuem para que essa noção de antidisciplinaridade seja vivenciada e 
estimula, assim, tanto um melhor diálogo entre as disciplinas e áreas do saber quanto permite que ideias não previsíveis surjam. Ou seja, o que se verifica é uma possibilidade de os laboratórios atuarem como transformadores da cultura que compartimenta o conhecimento em áreas para uma cultura que tem uma linguagem comum entre as diferentes disciplinas.

\subsubsection{Tolerância ao erro}

Outro valor importante na cultura desses espaços é a aceitação do erro como parte importante na aprendizagem e na experimentação.

Os processos ligados a manusear ferramentas e equipamentos pela primeira vez, a entender como funcionam novas tecnologias e plataformas, bem como a pensar de forma aplicada ao construir protótipos e artefatos físicos trazem uma série de novidades e tiram os participantes da sua zona de conforto. Naturalmente, erros e tentativas frustradas são corriqueiros, e ajudam a construir uma cultura de maior liberdade experimental e menor necessidade de respostas rápidas e prontas.

Isso é importante quando se tem em mente que diversos pesquisadores já afirmaram que "algumas das melhores ideias vêm de nossas falhas" (STAPPERS; GIACCARDI, s/d) ou que "o erro promove outras formas de fazer as coisas" (Chris Hay, 2016, p. 76). E apesar dos potenciais ganhos que o erro enseja, a sua valorização ainda é pouco presente em nossas organizações (incluindo os espaços educacionais). Como escreve Amy C. Edmondson (2011):

Fracassos e culpa são praticamente inseparáveis na maioria das famílias, organizações e culturas. Toda criança aprende em algum momento que admitir 0 fracasso significa assumir a culpa. É por isso que tão poucas organizações mudaram para uma cultura de segurança psicológica na qual as recompensas do aprendizado do fracasso podem ser plenamente realizadas.

Em O presente do erro (de 2015), analisado por Megan Egbert, Jessica Lahey descreve por que esses pequenos erros que acompanham o fazer importam, e ressalta que o erro é essencial para o processo de aprendizagem. A autora explica que, quanto mais fácil é recuperar uma informação, mais o nosso cérebro tende a esquecê-la. $E$ ao se promoverem desafios que 0 estimula, mais 0 aprendizado ficará na nossa parte do cérebro que lida com 0 longo prazo (EGBERT, 2016, p. 29). Elizabeth e Robert Bjork chamaram esses desafios de "dificuldades desejáveis" e Egbert afirma que o fazer tem um potencial grande de promovê-los, pois "possui resultados desconhecidos e requer tentativa e erro de design para criar um produto final" (2016, p. 29). 


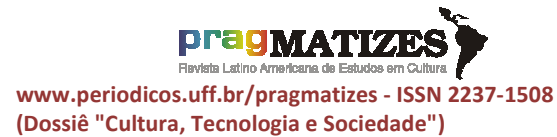

Matthew Sanders, em Becoming a Learner (2012), aponta a diferença entre um estudante e um aprendiz e reforça que é justamente o medo de errar do primeiro que o distancia do segundo.

Egbert propõe que o aprendiz de Sanders seja substituído pela figura do maker. $\mathrm{O}$ autor constata como os frequentadores dos espaços de fazer entendem o aprendizado - isto é, de uma maneira mais ativa e auto direcionada - e associa isso diretamente à cultura do erro que existe nesses espaços:

No processo de fazer, porque o produto geralmente é funcional - ou se destina a existir - há muito espaço para falhas. Os robôs não se movem, a solda não fica presa, o trabalho de impressão é interrompido, as estruturas quebram, os circuitos não são concluídos e o gravador de vídeo nunca é ligado para começar. Tudo oferece uma ampla oportunidade de comprometer o aprendizado à memória de longo prazo. O fazer é feito de dificuldade desejável em cima da dificuldade desejável. Seu desafio é encontrar uma maneira de manter os alunos em movimento, pensando neles, para que possam obter os benefícios duradouros de criar (EGBERT, 2016, p. 30).

No vídeo Por que você deveria fazer coisas inúteis ${ }^{6}$, feito para a plataforma TED e visualizado mais de

\footnotetext{
${ }^{6}$ Disponível em:

https://www.ted.com/talks/simone_giertz_why you_should_make_useless_things. Acesso: 10 fev. 2020 .
}

3,48 milhões de vezes, Simone Giertz conta como construir robôs propositalmente inúteis substituiu as pressões e expectativas por entusiasmo e Ihe permitiu experimentar mais e, assim, aprender uma série de conteúdos.

A verdadeira beleza de fazer coisas inúteis é esse reconhecimento de que nem sempre você sabe qual é a melhor resposta. (...) Isso desliga a voz em sua mente que diz que você sabe exatamente como o mundo funciona. Talvez um capacete de escova de dentes não seja a resposta, mas pelo menos você está fazendo a pergunta (GIERTZ, 2018).

Além de "robôs inúteis", Giertz também produz objetos que funcionam, como a Truckla ${ }^{7}$, uma versão caminhonete de um carro Tesla feita por ela mesma. processo de transformação do carro foi assistido mais de 11 milhões de vezes em um ano e foi matéria de capa da revista Wired. Na entrevista, Gierzt conta como construir pequenos objetos criativos e sem sentido, ou seja, com permissão para errar, a levou ao estágio de buscar desenvolver ambiciosos projetos de design e engenharia (GOODE, 2019).

Em conversa entre Giertz e Kevin Kelly ${ }^{8}$, fundador da Revista Wired ${ }^{9}$, Kelly

\footnotetext{
${ }^{7}$ https://www.youtube.com/watch?v=jKv_NOID S2A\&feature=youtu.be.

${ }^{8}$ Disponível em:

https://www. youtube.com/watch?v=zzF3ncrn_w. Acesso: 10 fev. 2020.

${ }^{9} \mathrm{https}: / /$ www.wired.com/.
} 


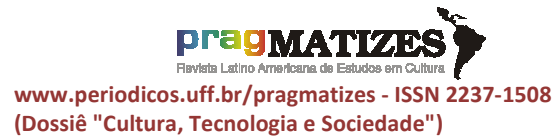

afirma que o erro precisa ser aceito e bem-vindo. "Faça coisas que falhem", recomenda.

\begin{abstract}
Podemos aprender quase tanto com um experimento que não funciona quanto com um que funciona. $O$ fracasso não é algo a ser evitado, mas algo a ser cultivado. Essa é uma lição da ciência que beneficia não apenas a pesquisa de laboratório, mas 0 design, 0 esporte, a engenharia, a arte, 0 empreendedorismo e até a própria vida cotidiana. Todas as vias criativas produzem o máximo quando as falhas são adotadas. Um ótimo designer gráfico gerará muitas ideias, sabendo que a maioria será abortada. Um grande dançarino percebe que a maioria dos novos movimentos não terá sucesso. O mesmo vale para qualquer arquiteto, engenheiro elétrico, escultor, maratonista, amador ou microbiologista. Afinal, o que é ciência, senão uma maneira de aprender com as coisas que não funcionam e não apenas com as que funcionam? O que esta ferramenta sugere é que você busque o sucesso enquanto está preparado para aprender com uma série de fracassos. Além disso, você deve, com cuidado, mas deliberadamente, pressionar suas investigações ou realizações bem-sucedidas a ponto de quebrar, fracassar, parar, travar ou falhar (KELLY, 2011).
\end{abstract}

Promover uma maior abertura para o erro, entendendo os resultados negativos como parte importante do processo de aprendizagem, é um dos maiores valores dos laboratórios. E esse valor se incorpora não apenas no processo de tentativa e erro, próprio das construções de artefatos, mas também no estímulo a quebrar sistemas em funcionamento, como forma de entender os seus limites e impulsioná-los em direção a melhorias.

\subsubsection{Diversidade cognitiva}

Outro ponto importante para garantir que os espaços experimentais contribuam para a transformação cultural do seu entorno e estimulem reflexão e produção crítica é a capacidade de gerar diversidade de pensamentos, já que diversidade de "raça, gênero, situação socioeconômica, área do conhecimento são importantes, mas somente na medida em que são elementos para os tipos de experiências que produzem diversidade cognitiva" (ITO, 2016, p. 184).

Diversidade cognitiva, por sua vez, é definida como a extensão em que o grupo reflete diferenças de conhecimento, incluindo crenças, preferências e perspectivas (MILLER et al, 1998) e vem cada vez mais sendo apontada como fator importante para a construção de conhecimento nas organizações, como escrevem Rebecca Mitchell e Stephen Nicholas (2006, p. 67-74).

Ito afirma que, como é impossível saber antecipadamente quais dos diversos fatores, experiências educacionais ou tendências intelectuais podem produzir grandes avanços, 


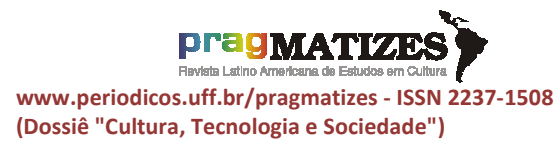

"devemos pensar em nossas diferenças como forma de talento".

Para Mitchell e Nicholas, "a integração de diversas perspectivas e conhecimentos previamente desconectados sustenta a geração de novos conhecimentos". Eles explicam que os grupos se comportam de modo mais eficaz na criação de conhecimento "quando [seus] membros individuais acreditam na liberdade de expressão e valorizam a compreensão e a utilização de pontos de vista divergentes" (MITCHELL; NICHOLAS, 2006, p. 71) ${ }^{10}$.

A democratização da internet permitiu que organizações pudessem aderir a novas formas de trabalho, ampliando assim a diversidade de suas equipes (e, por consequência, a geração de conhecimento organizacional).

Cite-se 0 exemplo de Matt Mullenweg, analisado em artigo de Romain Dilliet. O empresário da indústria de tecnologia fundou, no início dos anos 2000, uma empresa de software que, em 2019, valia mais de US\$ 3 bilhões. Ela opera em um modelo descentralizado, ou seja, não possui uma sede central e contrata colaboradores em vários países do mundo (DILLIET, 2019). Mullenweg é o CEO da Auttomatic, empresa por trás do WordPress.com, Jetpack e Woo

\footnotetext{
${ }^{10}$ Embora alertem para o fato de que essa mesma diferença de pensamentos é, muitas vezes, geradora de conflitos interpessoais.
}

Commerce, que juntas somam novecentos funcionários. Para ele, a distribuição geográfica dos funcionários gera uma grande força para a empresa, já que acredita, conforme relata para a plataforma TED, que:

Talento e inteligência estão igualmente distribuídos pelo mundo. Mas a oportunidade não está. No Vale do Silício, as grandes empresas de tecnologia basicamente pescam na mesma pequena lagoa ou baía. Uma empresa distribuída pode pescar em todo o oceano. Em vez de contratar alguém no Japão, que mora na Califórnia, você pode contratar alguém que acorda e vai dormir onde quer que esteja no mundo. Eles trazem uma compreensão diferente dessa cultura e experiência de vida diferente ${ }^{11}$.

Essa noção de inteligência distribuída cooperando com as organizações sustenta as ações de crowdsourcing, "um modelo on-line distribuído de solução de problemas e produção que aproveita a inteligência coletiva das comunidades on-line para atender a objetivos organizacionais específicos", conforme explica Daren C. Brabham (2013, p. XIX).

Por meio do crowdsourcing ${ }^{12}$, pessoas com experiências muito variadas,

\footnotetext{
${ }^{11}$ https://www.ted.com/talks/matt_mullenweg_w hy_working_from_home_is_good_for_busines s? language $=$ pt-br\#t-94932.

${ }^{12}$ Exemplos comuns: o aplicativo de trânsito Waze, que se baseia na informação coletada do celular de cada usuário; desafios lançados
} 
de contextos distintos, podem trazer um olhar diferente para um determinado problema e ajudar a resolvê-lo ou tornar ainda mais complexos os questionamentos propostos pelo problema. Ito cita um estudo ${ }^{13}$ da escola de administração de Harvard, que constata uma relação entre soluções bemsucedidas e o que o pesquisador Karim Lakhani chamou de "distância do campo": "numa linguagem simples, quanto menos um determinado solucionador estiver exposto à disciplina em que o problema reside, mais propenso ele está de resolvêIo" (ITO, 2016, p. 182, citando Lakhani, Jeppesen, Lohse \& Panetta, 2006).

Nesse sentido, criar uma cultura convidativa à diversidade de pensamentos, atraindo pessoas com perfis variados em relação a gênero, raça, idade, orientação sexual, condição social, naturalidade, grau de instrução, área de conhecimento, religião, gostos, interesses, entre outros, é uma forma de garantir que os laboratórios sejam berços de novas ideias e questionamentos, abraçando, inclusive, pontos de vista não óbvios.

por empresas para fazer pesquisa e desenvolvimento ou melhorar algum outro processo interno, como os realizados pela marca Adidas nos últimos anos (PERRY, 2018).

${ }^{13} \mathrm{https}: / /$ www.hbs.edu/faculty/Publication\%20Fi les/07-050_1b57659d-78f0-4686-a764925531f05a7b.pdf.

\section{Conclusão}

A noção de que os artefatos resultam do diálogo entre os materiais e os seus criadores, e não necessariamente da materialização de ideias préplanejadas, mostra como as atividades manuais podem estimular o surgimento de novas questões e formas de pensamento. $E$, por isso, essa noção embasa atividades e metodologias focadas no desenvolvimento da criatividade, inclusive dentro de instituições formais.

Com a evolução da computação, criar e testar sistemas tecnológicos avançados de forma simples e acessível não está mais restrito ao desenvolvimento de códigos na camada do software, e pode ocorrer, por exemplo, na junção dos códigos com circuitos eletrônicos e com o design da estrutura física feita por meio de técnicas muito variadas (incluindo uso de impressoras 3D ou até mesmo sucata).

Essas junções e linguagens têm guiado $o$ trabalho em escolas e universidades, misturando inclusive atividades manuais tradicionais com sistemas computacionais. Isso tem sido feito tanto para estimular o aprendizado de habilidades técnicas (em conceitos ligados a ciências, tecnologia, engenharia, artes e matemática, o assim chamado STEAM, do acrônimo em inglês), quanto para estimular habilidades socioemocionais, tais como trabalho em equipe, criatividade, solução de problemas 


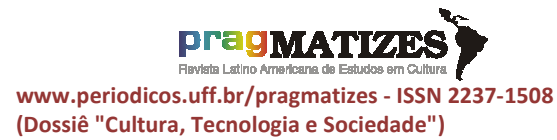

e pensamento crítico. As políticas de incentivo ao ensino de STEAM impulsionaram a criação de laboratórios, usualmente chamado de makerspaces, em escolas, universidades e museus em diversos países.

Este trabalho mostra que os labs, sejam independentes

ou institucionalizados, podem atuar para: (1) estimular a conexão entre as diversas áreas do saber; (2) conectar questões teóricas com as questões práticas, colaborando para soluções ligadas a problemas macro e do cotidiano; (3) dar visibilidade à diversidade de pensamentos, ideias e visões de mundo; e (4) permitir que ideias, aparatos, produtos e processos novos surjam como resultado da exploração guiada por tentativa e erro. Ou seja, é justamente o caráter de experimentação que deve estar no cerne desses espaços para que eles consigam estimular a curiosidade e promover reflexão crítica - evitando se converter em um mero ambiente de infraestrutura nova, mas que segue velhas práticas - ou ainda um espaço vazio, sem engajamento de participantes.

O presente artigo parte da perspectiva de que esses espaços podem ter um impacto efetivo na cultura do seu entorno (seja ele uma escola, uma empresa, um museu, um centro de pesquisa, uma universidade ou mesmo um bairro) quando são convertidos em lugar real de experimentação e assim dão vazão à investigação proveniente da aguçada curiosidade humana. Para que, então, os labs estimulem questionamentos e produção crítica, convido a reflexão a respeito de um grupo de valores que acredito serem importantes nesse tipo de experiência:

\section{- $\quad$ Antidisciplinaridad}

e: é fundamental que esses espaços permitam pensamentos não óbvios e que não se encaixem facilmente nas disciplinas consolidadas, entendendo a relação entre o conhecimento e 0 exercício do aprendizado como uma troca fluida. Nesse sentido, vale resgatar 0 conceito de antidisciplinaridade apresentado por Neri Oxman, que remete à ideia de que existem projetos e pensamentos que não se encaixam em nenhuma disciplina acadêmica tradicional, "porque trabalham no espaço em branco que está entre - ou simplesmente além - das disciplinas", como resume Ito. Em modelo conceitual criado por ela, a hipótese antidisciplinar indica que 0 conhecimento não pode mais ser atribuído a, ou produzido dentro de limites disciplinares, pois está totalmente enredado.Esse olhar integrador é importante não para 


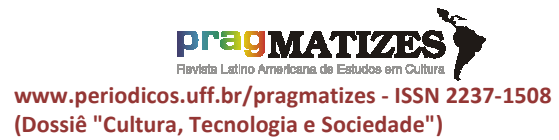

eliminar as disciplinas já existentes, mas para que os espaços colaborem no necessário diálogo entre especialistas das diversas áreas do conhecimento com foco na construção conjunta, e não apenas na colaboração entre as disciplinas (a qual remete ao conceito de interdisciplinaridade).

\section{- Tolerância ao erro:} encarar os insucessos como parte de uma jornada de aprendizagem é fundamental para a geração de ideias e a exploração de novas linguagens. $\mathrm{Na}$ manipulação de materiais e tecnologias que ocorrem nos labs, erros e tentativas frustradas são comuns e criam uma cultura de mais liberdade experimental e menor necessidade de produzir respostas prontas. E é justamente esse o papel dos labs: estimular o "aprender a aprender", de uma maneira ativa e auto direcionada; e não mais o aprender como uma capacidade de absorção de conteúdos para a sua reprodução ou imediata aplicação. Aceitar o erro é indispensável para que os espaços de fazer não virem um lugar de reprodução e "cópia" de conteúdos previamente elaborados e, com isso, percam a sua capacidade de estimular pensamento crítico.

\section{- Diversidade}

cognitiva: estimular que os labs sejam frequentados por grupos heterogêneos e diversos, do ponto de vista de gênero, raça, situação socioeconômica, área de atuação, idade e religião, permite uma ampliação de visões tanto no processo de aprendizagem quanto no desenvolvimento de artefatos. Entender nossas diferenças como talentos é uma forma importante para estimular uma cultura que convida olhares diferentes e, a partir delas, gera questionamentos e ideias. Um espaço que reúne artistas e engenheiros tende a estar mais próximo de atender os quatro objetivos listados acima do que um que reúne apenas estudantes de engenharia, por exemplo.

Esses valores, longe de representar uma conclusão pronta e acabada, são apenas um ponto de partida para que outros olhares sejam somados na busca de entender como esses 


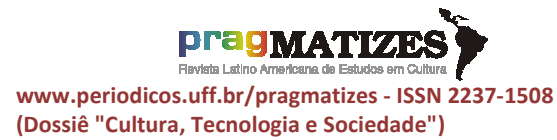

ambientes podem ser mais bem aproveitados para estimular que as inovações do século XXI reflitam as preocupações de um conjunto mais amplo de agentes da sociedade.

Nesse sentido, cabe lembrar que as tecnologias e novas ferramentas podem contribuir de imediato com questões sociais urgentes (como a erradicação da pobreza, a justa distribuição de alimentos pela população mundial, a mitigação das mudanças climáticas, a redução das desigualdades sociais), ao escalar soluções, otimizar fluxos e processos, por exemplo. E elas podem também contribuir para materializar ideias que especulem sobre futuros desejáveis, permitindo, inclusive, maior entendimento dos desafios que moldam o presente.

Imaginar como o futuro pode ser passa por redefinir a nossa relação com a realidade. E levanta possibilidades que podem ser discutidas, debatidas e usadas para definir coletivamente um futuro preferível ou desejável. Nesse sentido, os espaços de fazer podem ser uma infraestrutura que traga à tona os sonhos coletivos e nos inspire "a imaginar que as coisas podem ser radicalmente diferentes do que são hoje, e acreditar que podemos progredir em direção a esse mundo imaginário", tal como descrevem Dunne e Raby.
Dessa forma, os espaços de fazer podem desempenhar papel similar ao papel do design/designer defendido por Dunne e Raby no processo de construção de futuros:

Designers não devem definir futuros para todos os outros, mas trabalhar com especialistas, incluindo especialistas em ética, cientistas políticos, economistas e outros, gerando futuros que atuam como catalisadores para o debate público e a discussão sobre os tipos de futuros que as pessoas realmente desejam. $O$ design pode dar aos especialistas permissão para deixar a imaginação fluir livremente, dar expressão material aos insights gerados, fundamentar essas imaginações nas situações cotidianas e fornecer plataformas para mais especulações colaborativas.

Acreditamos que, especulando mais, em todos os níveis da sociedade, e explorando cenários alternativos, a realidade se tornará mais maleável e, embora o futuro não possa ser previsto, podemos ajudar a estabelecer hoje fatores que aumentarão a probabilidade de futuros mais desejáveis acontecerem. E, igualmente, fatores que podem levar a futuros indesejáveis podem ser identificados desde o início e ser abordados ou pelo menos limitados (DUNNE; RABY, 2013, p. 6).

É a partir desta abordagem que o presente artigo buscou evidenciar a importância da existência de espaços de experimentação tecnológica como fomentadores de uma cultura em que os 
AGUSTINI, Gabriela da Costa Aguiar; SANTOS, Jorge Roberto Lopes dos. Espaços de fazer como geradores de uma cultura pautada pela antidisciplinaridade, tolerância ao erro e diversidade cognitiva. PragMATIZES - Revista Latino-Americana de Estudos em Cultura, Niterói/RJ, Ano 10, n. 19, p. 30-50, set. 2020.

cidadãos possam assumir o protagonismo e construir juntos outros futuros possíveis.

\section{Referências bibliográficas}

ACKERMANN, E. K. Give me a place to stand and I will move the world! Lifelong learning in the digital age. Journal for the Study of Education and Development. Volume 38, Issue 4, $2015 . \quad$ Disponível em: https://www.tandfonline.com/doi/full/10. 1080/02103702.2015.1076265.

Acesso: 10 mar. 2020.

BLIKSTEIN, P. Maker Movement in Education: History and Prospects. In: M.J. de Vries (ed.). Handbook of Technology Education. Springer International, 2018.

BLIKSTEIN, P. O mito do mau aluno e porque o Brasil pode ser o líder mundial de uma revolução educacional. Sem data. Disponível em: http://blikstein.com/paulo/documents/b ooks/Blikstein-

Brasil_pode_ser_lider_mundial_em_ed ucacao.pdf. Acesso: 15 mar. 2020.

DAUGHERTY, M. K. The Prospect of an "A" in STEM Education. Journal of STEM Education, Volume 14, Issue 2, abr.-jun. 2013. Disponível em: https://www.jstem.org/jstem/index.php/ JSTEM/article/view/1744/1520.

Acesso: 5 mar. 2020.

DOUGHERTY, D. Free to Make: How the Maker Movement Is Changing Our Schools, Our Jobs, and Our Minds. North Atlantic Books, 2016.

DOUGHERTY, D. The Maker Movement. MIT Press Journals, 2012. Disponível em: https://www.mitpressjournals.org/doi/p

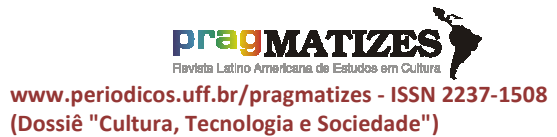

df/10.1162/INOV_a_00135. Acesso: 10 mar. 2020.

DUNNE, A.; RABY, F. Speculative Everything: Design, Fiction, and Social Dreaming. Cambridge, Massachusetts: The MIT Press, 2013.

EDMONDSON, A. Strategies for Learning from Failure. Harvard Business Review. Edição Abril de 2011. Disponível em: https://hbr.org/2011/04/strategies-forlearning-from-failure. Acesso: 10 mar. 2020.

EGBERT, M. Creating Makers: How to Start a Learning Revolution at Your Library. Libraries Unlimited, 2016.

GARBER, E.; HOCHTRITT, L.; SHARMA, M. Introduction. In: Makers, Crafters, Educators: Working for Cultural Change. Oxford: Routledge, 2019.

GOODE, L. Why the 'Queen of Shitty Robots' Renounced Her Crown. Wired magazine, 12 out. 2019. Disponível em:

https://www. wired.com/story/simonegiertz-build-what-you-want/. Acesso: 10 mar. 2020.

GORE, N. Craft and innovation: Serious play and the direct experience of the real. Journal of Architectural Education, Volume 58, Issue 1, p. 3944, 2004.

HALVERSON, E.; SHERIDAN, K. M. 2014. The Maker Movement in Education. Harvard Educational Review, Vol. 84, No. 4, inverno de $2014 . \quad$ Disponível em: https://www.semanticscholar.org/paper /The-Maker-Movement-in-EducationHalverson-

Sheridan/66147755ddbaaa159bd5c59 bcfad72f33e5c427b. Acesso: 7 mar. 2020. 
INGOLD, T. Making: Anthropology, Archaeology, Art and Architecture. Onxford: Routledge, 2013.

ITO, J. Design and Science: Can design advance science, and can science advance design? Journal Of Desing and Science, 12 jan. 2016. Disponível em: https://jods.mitpress.mit.edu/pub/desig nandscience. Acesso: 20 mar. 2020.

ITO, J.; HOWE, J. Disrupção e inovação: como sobreviver ao futuro incerto. Rio de Janeiro: Alta Books, 2018.

KELLY, K. What scientific concept would improve everybody's cognitive toolkit?2011. Disponível em: https://www.edge.org/responsedetail/10422. Acesso: 5 mar. 2020.

LAND, M. H. Full STEAM Ahead: The Benefits of Integrating the Arts Into STEM. Procedia Computer Science, Volume 20, p. 547-552, 2013.

LEITE, P. P. Sobre a distinção entre história e evolução em Tim Ingold. Social Evolution \& History, Vol. 1, No. 1, p. 5-24, jul. 2002. Disponível em: https://globalherit.hypotheses.org/6719 Acesso: 9 mar. 2020.

MARCHAND, T. H. J. Learning, Education and Apprenticeship. Journal of the Royal Anthropological Institute, 18 (1). p. 209-210, 2012.

MITCHELL, R.; NICHOLAS, S. Knowledge Creation in Groups: The Value of Cognitive Diversity, Transactive Memory and Openmindedness Norms. Electronic Journal of Knowledge Management, Volume 4, Issue 1, p. 67-74, 2006. Disponível em: https://www.researchgate.net/publicati on/220826009_Knowledge_Creation_i n_Groups_The_Value_of_Cognitive_Di versity_Transactive_Memory_and_Op enmindedness Norms. Acesso: 5 mar. 2020.

OXMAN, N. Age of Entanglement. 2016. Disponível em: https://jods.mitpress.mit.edu/pub/AgeO fEntanglement. Acesso: 3 mar. 2020.

SANDERS, M. Becoming a Learner. Realizing the Opportunity of Education. Institute for Communication \& Leadership, 2012.

SILVA, R. B.; MERKLE, L. E. Perspectivas educacionais FabLearn: conceitos e práticas maker no Brasil. In: Fablearn Conference, 2016. Disponível em: https://www.researchgate.net/publicati on/308098069_Perspectivas_educacio nais_FabLearn_conceitos_e_praticas maker_no_Brasil. Acesso: 5 mar. 2020.

SNOWDEN, E. Eterna vigilância: como montei e desvendei o maior sistema de espionagem do mundo. São Paulo: Planeta, 2019.

STAPPERS, P.; GIACCARDI, E. Research through Design. The Encyclopedia of Human-Computer Interaction, 2nd Ed., Sem data.

Disponível em: https://www.interactiondesign.org/literature/book/theencyclopedia-of-human-computerinteraction-2nd-ed/research-throughdesign 